\title{
Self-Efficacy Intervention Programs in Patients with Chronic Obstructive Pulmonary Disease: Narrative Review
}

\author{
Qi-Feng $\mathrm{Yi}^{\prime}$ \\ Guo-Li Yang ${ }^{2}$ \\ Jin $\mathrm{Yan}^{3}$
}

'Nursing Teaching and Research Department, Third Xiangya Hospital of Central South University, Changsha, People's Republic of China; ${ }^{2}$ Department of Respiration, Third Xiangya Hospital of Central South University, Changsha, People's Republic of China; ${ }^{3}$ The Nursing Department, Third Xiangya Hospital of Central South University, Changsha, People's Republic of China
Correspondence: Jin Yan Email jinglaihaohui6889@163.com

\begin{abstract}
Chronic obstructive pulmonary disease (COPD) is a common chronic disease whose development is irreversible, which leads to more than six million deaths each year. There is no treatment confirmed effective for the improvement of impaired lung function, but the combination of drug therapy with non-drug therapy such as pulmonary rehabilitation training has demonstrated a great potential in reducing the occurrence of complications and delaying the progression of COPD. Self-efficacy is the core of cognitive theory, which is crucial for chronic disease management. It has been proposed as an important component of disease management to help people develop skills to manage diseases more effectively. This study reviewed the development of self-efficacy and its application in patients with COPD, with the purpose of providing a better clinical reference for the treatments of COPD.

Keywords: self-efficacy, chronic obstructive pulmonary disease, pulmonary rehabilitation, quality of life, nursing
\end{abstract}

\section{Introduction}

Chronic obstructive pulmonary disease (COPD) is a common chronic disease characterized by continuous airflow limitation, which is related to a more intense chronic inflammatory response of the respiratory tract and lungs to toxic particles or gases. ${ }^{1}$ It can further develop into a serious disease (such as pulmonary heart disease and respiratory failure) with a high disability rate and fatality rate. The global incidence rate of COPD among the population over 40 years old changes in the title of the manuscript reached $9 \%$ to $10 \%{ }^{2}$ COPD has an elusive pathogenesis that is speculated to be related to the development of chronic bronchitis and obstructive pulmonary emphysema. ${ }^{3}$ Its irreversible development may result in declines in lung function, exercise endurance, and work disability, which seriously compromises patients' quality of life. ${ }^{4-6}$ Currently, the absence of effective treatment for the improvement of lung function entails disease control in the stable stage. ${ }^{7}$ Self-efficacy is a new nursing concept developed based on the new concept of bio-psycho-social medicine, which has been widely adopted in chronic disease management and has yielded promising effects in COPD. ${ }^{8}$ This study reviewed self-efficacy intervention programs in patients with chronic obstructive pulmonary disease, so as to provide scientific reference for the treatment of COPD.

\section{Concept and Development of Self-Efficacy}

As a core concept in the theory of social cognition, self-efficacy refers to an individual's judgment and confidence in his/her ability to successfully implement 
and achieve a certain behavior goal or solve a certain difficulty, or the individual's understanding and feeling of self-ability. Self-efficacy mainly benefits from mastery, modeling, and interpretation of symptoms and social persuasion skills. ${ }^{9}$ In response to difficult tasks, individuals with a high self-efficacy may complete the tasks as better as possible, while those with a low self-efficacy are prone to evade them. Self-efficacy in nursing was first applied to childhood asthma, which significantly boosted the treatment effect and children's confidence against the disease. In the 1970s, Bandura has summarized the concept of selfefficacy as the degree of self-confidence of an individual to his/her ability to achieve expected results, believing that self-efficacy is neither a skill nor a true ability, but the degree of confidence. ${ }^{10}$ Self-efficacy intervention aims to achieve a healthy lifestyle by behavior regulation. ${ }^{11}$ Based on the new concept of the bio-psycho-social medicine model, Nakagawa has defined the self-efficacy intervention of patients with chronic diseases as an intervention method that integrates the patient's physiological, psychological, and social factors, and close observation and prompt handling of disease symptoms are conducive to alleviating the impact of the disease. ${ }^{12}$ Corbin has summarized self-efficacy into three categories: ${ }^{13}$ (1) Disease management: the patient's ability to cope with their diseases, including taking medication, diet, exercise, and selfsymptom monitoring as prescribed by the doctor; (2) Role management: the patient's ability to maintain his/her role in daily life, covering housework, maintenance work, and social activities within his/her ability; (3) Emotion management: the patient's ability to control negative emotions, including anxiety, depression, pessimism, and panic. In recent years, self-efficacy that involves the beneficial behaviors of both doctors and patients, that is, health education for medical staff and active health behaviors of patients, has been widely adopted in care of patients with chronic disease. Accordingly, self-efficacy can be summarized into the following aspects: (1) Self-efficacy emphasizes individual social cognition and individual selfrationality; (2) Self-efficacy is oriented by patients' concerns; (3) The purpose of self-efficacy is not limited to the cure of diseases but also includes the establishment and maintenance of healthy behaviors; (4) Self-efficacy requires certain knowledge and skills. Recently, an international panel of experts conceptually defined that selfmanagement interventions should be structured, but also individualized, and often multi-component, with the goal of actively motivating, engaging, and supporting patients to adjust their behaviors and develop better management skills for their diseases. ${ }^{14}$

\section{Self-Efficacy Assessment Methods for Patients with COPD}

Compared with healthy individuals, the daily physical activity of patients with COPD is critically impaired so that they walked less with a lower intensity and thus had an inadequate physical activity level. ${ }^{15}$ More than a feature of COPD, the insufficiency of physical activity may also exist before the onset of dyspnea. ${ }^{16}$ Patients with COPD have poor exercise due to the influence of factors about physiology, behavior, society, environment, culture, and others. The lack of confidence in exercises whose impact on the body is likely to be ignored is considered as low self-efficacy. Wigal et al ${ }^{17}$ first proposed the COPD SelfEfficacy Scale (CSES) to evaluate the self-efficacy of patients with COPD. For patients with COPD confirmed to be with a low self-efficacy, specific interventions are required to improve their self-efficacy to enhance the treatment effect. CSES contains 34 items in 5 dimensions, including negative influence, psychological stress, physical exertion, weather/environment, and behavioral hazards. The Likert 5-level score ranges from 1 point (completely unconfident) to 5 points (completely confident) from high to low. Müller et al translated the CSES scale into German (CSES-D) and recruited 199 patients with COPD to analyze the factorial structure of the five dimensions of CSES from exploratory factor analysis and confirmatory factor analysis, and finally confirmed the excellent internal consistency of psychological stress $(\alpha=0.95)$ and physical exertion $(\alpha=0.92)$ subscales. $^{18}$ In addition, the Danish, Norwegian, and Korean versions of the CSES scale have also been widely developed and applied for patients with COPD in different countries, with the Cronbach's $\alpha$ coefficient ranging from 0.75 to 0.94 and the test-retest reliability from 0.55 to $0.75 .{ }^{19-21}$

Pulmonary Rehabilitation Adapted Index of SelfEfficacy (PRAISE) is a pulmonary function-related selfefficacy questionnaire developed by Vincent based on the GSES scale to measure the self-efficacy of patients participating in pulmonary rehabilitation. ${ }^{22}$ There are 15 items in PRAISE, including 10 items for "general" self-efficacy (from the GSES scale) and 5 items for self-efficacy about pulmonary rehabilitation. Research by Athina reveals that with a high predictive validity, PRAISE may contribute to the identification of those with a high self-efficacy so that 
more comprehensive health behavior changes can be achieved in pulmonary rehabilitation. ${ }^{23}$

In addition, on the basis of CSES, it has also derived exercise self-regulation efficiency energy scale (ExSRES), walking self-efficacy questionnaire, dyspnea selfefficacy energy scale, and smoking cessation self-efficacy energy scale. They are used to specifically assess the selfefficacy of a certain aspect of patients with COPD, but their widespread application has yet been seen in clinical practice. $^{24,25}$

\section{Self-Efficacy Status and Influencing Factors of Patients with COPD}

Since being first applied by Devins to the management of patients with COPD in 1988, self-efficacy has found rapid development and wide application in the past decades. ${ }^{26}$ Lee used the CSES scale to investigate the self-efficacy of 151 inpatients with COPD, ${ }^{27}$ and Ozkaptan employed it to evaluate the self-efficacy of 106 such patients in respiratory outpatient clinics. ${ }^{28}$ Their results all revealed a low self-efficacy of patients with COPD and positive correlations of the patients' grasp of respiratory function exercise skills, necessity and implementation methods with their self-efficacy, indicating the significance of health education in the improvement of patients' self-efficacy.

Low self-efficacy is reflected by the loss of confidence, reluctance to proper exercise, and low medication compliance owing to the characteristics of COPD (slow development, long course of the disease, and incurability) and problems such as breathing difficulties. The self-efficacy status of patients with COPD is affected by a variety of factors such as general social factors, disease states, and psychological conditions. Research has revealed a negative correlation between self-efficacy of patients with COPD and age, and found the cause was involved in the deterioration of body function, weakened disease tolerance, and decreased understanding ability. ${ }^{29}$ There are differences in self-efficacy of different genders. The selfefficacy of male patients is better than that of females of the same age, which may be explained by the high mental endurance of men and their strong sense of family responsibility. ${ }^{30}$ In addition, self-efficacy is closely related to the level of education. Patients with a higher level of education have a deeper understanding of the disease, better mastery of rehabilitation methods, and stronger confidence in their treatment. Moreover, self-efficacy is also related to family economic status. Patients with a heavier financial burden showed worse treatment completion, and thus may suffer rapid progress of the disease. ${ }^{31}$ There is also a relationship between self-efficacy of patients with COPD and severity of the disease and physiological function. A more severe disease and more acute episodes cause worse self-efficacy. Results of the study by Liacos showed that pulmonary rehabilitation exercises can significantly improve the lung function of patients with COPD, thereby enhancing their self-efficacy. ${ }^{32}$ Furthermore, self-efficacy is also an important indicator that affects the effect of pulmonary rehabilitation. It is worth noting that psychological conditions are also of great significance. A high incidence of unhealthy emotions such as anxiety and depression due to dyspnea, restricted daily activities, longterm medication, and heavy financial burdens has been found among patients with COPD. Accordingly, in the treatment of patients with COPD, close observation for the changes in psychological state, active communication and timely handling of negative emotions can promote the maintenance and alleviation of their disease condition. Symptom experience is an individual's perception of the frequency, intensity, degree of distress, and nature of symptoms. Patients with COPD have a strong symptom experience, but long-term symptom experience will aggravate the negative perception of the disease and reduce their self-management, confidence and motivation. One study has shown that self-efficacy is negatively correlated with self-feeling burden and symptom experience, so strengthening patients' self-efficacy can considerably improve their symptom experience. ${ }^{33}$

\section{Impact of Self-Efficacy on COPD Patients' Quality of Life}

COPD-related comorbidities such as cardiovascular disease, osteoporosis, and diabetes may result in dysfunction and further reduce health-related quality of life (HRQoL) whose improvement is one of the main goals of the treatment and rehabilitation of patients with COPD. A Cochrane review of self-efficacy in COPD concluded that self-management was associated with higher healthrelated quality of life (HRQoL), less respiration-related and all-cause hospitalizations, and milder dyspnea. ${ }^{34}$ Care plans based on self-efficacy contributed to a small improvement in HRQoL compared with routine care, but were unlikely to affect mortality. Meta-analysis results verified a positive correlation of self-efficacy with HRQoL. COPD-specific self-efficacy measures, such as 
dyskinesia, motor tasks, and COPD symptoms, present a stronger correlation with HRQoL than general selfefficacy measures. According to one previous study, the HRQoL status of individual participants was also reported using the Visual Analogue Scale (VAS). The increase tend of VAS scores indicated that the HRQoL of self-efficacy intervention was better than that of routine care $((72.3 \pm \mathrm{SE}$ 3.1) vs (62.4 $\pm \mathrm{SE} 3.5)$ ). Again, these data are descriptive reports only. Garcia-aymerich reported that there was a slight but insignificant improvement in quality of life scores based on VAS scores at 1 year of follow-up in both groups (intervention: $1.56 \pm \mathrm{SD} 1.77$ vs control: $0.93 \pm \mathrm{SD}$ $2.11) .{ }^{35}$ In the theory of self-efficacy, human beings are the subject of behaviors, and their consciousness constantly dominates their own behaviors, which can reflect the human body's full potential. Self-efficacy is closely related to the psychological pressure and mental health status of patients with COPD, and it has an impact on their healthy behaviors such as living conditions, behavioral goal setting, personal motivation, and thinking patterns. Compared with conventional breathing training, self-efficacy training focuses on psychological care and guidance, promotes the training and rehabilitation process, and helps improve the rehabilitation effect and prognostic quality of life by boosting the subjective initiative of patients. Keil stated that self-efficacy was significantly related to the reduction of anxiety and depression levels and COPD-related disabilities, which indicates that self-efficacy, as a protective factor, helps people cope with COPD. ${ }^{36}$ Boeckxstaens et $\mathrm{al}^{37}$ found a lower mortality rate and a milder functional decline in the elderly COPD patients with a higher selfefficacy. One study by Kaplan et al has verified that selfefficacy is an important predictor of 5-year survival, but multivariate survival analysis revealed only a marginal effect of self-efficacy in case of controlled FEV1. ${ }^{38}$ In addition, Aline's research results have demonstrated correlations of higher emotional representation and lower selfefficacy in patients with stable COPD with more severe symptoms, worse HRQoL, and lower education level in them, ${ }^{39}$ and Blackstock has pointed out the prediction value of a relatively high baseline self-efficacy for the level of 6 minutes walking distance (6MWD). ${ }^{40}$ Selfefficacy is associated with treatment compliance. Khdour reported based on a 12-months follow-up that $78 \%$ of participants in the intervention group showed higher adherence to maintenance medications compared to $60 \%$ in the control group, reflecting fewer medication omissions in the intervention group than those in the control group. ${ }^{41}$
After the acute phase of COPD, most patients would prefer treatment at home, but they have lower ability to take care of themselves and need assistance in completing daily activities and rehabilitation training, and the caregiver has to shoulder mild to moderate burden of care. Additionally, patients with COPD pose a significant impact on the quality of life of the caregivers. Semiha Kar discussed the relationship between the self-efficacy of patients with COPD and the burden of caregivers. The self-efficacy level of 200 patients with stage II and stage III COPD was evaluated by CSES and the caregiver burden was assessed by the Caregiver Burden Scale. The results indicated that the elevation in self-efficacy of patients with COPD gave rise to a less affected health condition and daily life and a slighter burden on caregivers. $^{42}$

\section{Approaches to Improve Self-Efficacy of Patients with COPD}

The improvement of self-efficacy of patients with COPD contributes to their quality of life, confidence of selfmanagement, and recovery. Overall, approaches to improve self-efficacy mainly include four methods: direct experience method, alternative experience, verbal persuasion, and emotion regulation method, ${ }^{43}$ as shown in Table 1. The direct experience method refers to one's successful completion of certain behavior and personal experience of acquiring the ability, which is considered as the most powerful source of self-efficacy. The second is alternative experience, in which confidence is built through observation of others' performance and estimation of one's abilities that can be achieved by observing the performance of others as individual experience is limited. Alternative experience can be either real or imaginary, and one of its key forms is the image of task performance. ${ }^{44}$ Verbal persuasion refers to the use of encouragement from others to increase self-confidence. The emotion control method is the amelioration of self-confidence by eliminating negative emotions and establishing an optimistic attitude. $^{45}$ Mindful behavior training is also a common method to improve patients' self-efficacy. It is a psychological adjustment method in which the individual consciously maintains the self-will in the current internal or external experience without any self-evaluation. It encourages the patients to maintain an open and acceptive attitude, increase their will to face negative emotions, and free them from the burden of negative emotions. 
Table I Approaches to Improve Self-Efficacy

\begin{tabular}{|l|l|}
\hline Method & \multicolumn{1}{c|}{ Content } \\
\hline Direct Experience & $\begin{array}{l}\text { The most powerful source of self-efficacy, which refers to one's successful completion of certain behavior and personal } \\
\text { experience of acquiring the ability. }\end{array}$ \\
\hline $\begin{array}{l}\text { Alternative } \\
\text { Experience }\end{array}$ & $\begin{array}{l}\text { Either real or imaginary, and one of its key forms is the image of task performance, which is built through observation of } \\
\text { others' performance and estimation of one's abilities that can be achieved by observing the performance of others as } \\
\text { individual experience is limited. }\end{array}$ \\
\hline $\begin{array}{l}\text { Verbal Persuasion } \\
\text { Regulation }\end{array}$ & \begin{tabular}{l} 
Amelioration of self-confidence by eliminating negative emotions and establishing an optimistic attitude. \\
\hline
\end{tabular}
\end{tabular}

Mindfulness behavior training mainly covers body scanning technology, mindfulness exercise training, mindfulness relaxation, breathing, and five sense organs training.

Kara and Türkinaz ${ }^{46}$ conducted structured education on 60 patients with COPD. The specific measures included joint review of the patients' medical history by doctors and patients, affirmation of their positive performance and correction of their negative performance, formulation of individualized protocols (direct experience method), distribution of educational manuals and explanations (verbal persuasion) to them, patients' observation on other patients who succeeded in completing rehabilitation exercises (alternative empirical method), and organization of regular psychological counseling and communication with family members to understand the patients' emotional state (emotional control method). As a result, these patients obtained a significantly improved self-efficacy. Maddux ${ }^{45}$ adopted a task-based nursing mode and self-efficacy-based nursing mode for analysis of patients with COPD. The former mode included a specified rehabilitation plan for the patients and supervision of an on-time completion, and the later one encouraged the patients to engage in social activities, sports, and other activities in addition to rehabilitation exercises. The results presented no significant difference in the PR effect between the two groups of patients and a significantly increased physical activity ability of the patients based on the self-efficacy care mode that contributed to the improvement of their quality of life.

\section{Expectation}

To date, research on the self-efficacy of patients with COPD has achieved remarkable results. From the perspective of medicine and nursing, self-efficacy can promote patients' mastering of disease knowledge and rehabilitation skills, help them build confidence and cultivate good habits, and thus ensure a better treatment effect on them. From the perspective of health economics, self-efficacy can improve patients' compliance, avoid disease recurrence, delay disease progression, and reduce the incidence of complications, thereby saving medical resources and reducing the burden on patients and society. Due to the imperfect construction of community nursing system and the lack of disease knowledge of grassroots medical staff, the nursing of patients after discharge is interrupted and they cannot obtain professional health knowledge, resulting in inadequate self-monitoring and nursing of patients with diseases. ${ }^{47}$ The new nursing mode based on Internet plus mode provides ideas for the nursing of various chronic diseases, and can provide patients with multi-dimensional nursing services from hospitals, communities, families, etc., with high effectiveness and initiative, and high degree of acceptance by patients. ${ }^{34}$ Patients can obtain more disease information through the Internet, and communications between doctors and patients and between patients can be realized through video, of all which provide good conditions for improving self-efficacy. However, there are problems such as uneven research quality, varying length of research time, lack of standards for intervention measures, and insufficient reliability of evaluation methods. Internet plus mode provided more possibilities for selfefficacy nursing, which was a future development direction. Due to differences in patients' conditions and the ability and quality of nursing staff, notwithstanding a broad consensus that has been achieved on selfefficacy, there are still many limitations in nursing work, 
such as insufficient understanding and attention and ineffective measures, which require further effective solutions.

\section{Disclosure}

The authors report no conflicts of interest in this work.

\section{References}

1. Yentes JM, Fallahtafti F, Denton W, Rennard SI. COPD patients have a restricted breathing pattern that persists with increased metabolic demands. COPD. 2020;17(3):245-252. doi:10.1080/ 15412555.2020 .1750578

2. Baker E, Fatoye F. Clinical and cost effectiveness of nurse-led self-management interventions for patients with COPD in primary care: a systematic review. Int J Nurs Stud. 2017;71:125-138. doi:10.1016/j.ijnurstu.2017.03.010

3. Hattab Y, Alhassan S, Balaan M, Lega M, Singh AC. Chronic obstructive pulmonary disease. Crit Care Nurs Q. 2016;39 (2):124-130. doi:10.1097/CNQ.0000000000000105

4. Smith MC, Wrobel JP. Epidemiology and clinical impact of major comorbidities in patients with COPD. Int J Chron Obstruct Pulmon Dis. 2014;9:871-888. doi:10.2147/COPD.S49621

5. Zwerink M, Brusse-Keizer M, van der Valk PD, et al. Self management for patients with chronic obstructive pulmonary disease. Cochrane Database Syst Rev. 2014;2014(3):CD002990.

6. Yudhawati R, Rasjid HM. Effect of yoga on FEV1, 6-minute walk distance (6-MWD) and quality of life in patients with COPD group B. Adv Respir Med. 2019;87(5):261-268. doi:10.5603/ ARM.2019.0047

7. McFadden ER Jr. Natural history of chronic asthma and its long-term effects on pulmonary function. $J$ Allergy Clin Immunol. 2000;105(2 Pt 2):S535-9. doi:10.1016/S0091-6749(00)90057-5

8. Klassen RM, Klassen JRL. Self-efficacy beliefs of medical students: a critical review. Perspect Med Educ. 2018;7(2):76-82. doi:10.1007/ s40037-018-0411-3

9. Bandura A. Self-efficacy: toward a unifying theory of behavioral change. Psychol Rev. 1977;84(2):191-215. doi:10.1037/0033295X.84.2.191

10. Wright BJ, O'Halloran PD, Stukas AA. Enhancing self-efficacy and performance: an experimental comparison of psychological techniques. Res Q Exerc Sport. 2016;87(1):36-46. doi:10.1080/ 02701367.2015.1093072

11. Kim Y, Chung S, So J. Success expectancy: a mediator of the effects of source similarity and self-efficacy on health behavior intention. Health Commun. 2020;35(9):1063-1072. doi:10.1080/ 10410236.2019 .1613475

12. Nakagawa-Kogan H, Garber A, Jarrett M, Egan KJ, Hendershot S. Self-management of hypertension: predictors of success in diastolic blood pressure reduction. Res Nurs Health. 1988;11(2):105-115. doi:10.1002/nur.4770110206

13. Farley H. Promoting self-efficacy in patients with chronic disease beyond traditional education: a literature review. Nurs Open. 2019;7 (1):30-41. doi:10.1002/nop2.382

14. Allegrante JP, Wells MT, Peterson JC. Interventions to support behavioral self-management of chronic diseases. Annu Rev Public Health. 2019;40(1):127-146. doi:10.1146/annurev-publhealth-040218-044008

15. Albarrati AM, Gale NS, Munnery MM, Cockcroft JR, Shale DJ. Daily physical activity and related risk factors in COPD. BMC Pulm Med. 2020;20(1):60. doi:10.1186/s12890-020-1097-y

16. Coultas DB. Physical inactivity, self-management, and living well with COPD. Am J Lifestyle Med. 2017;11(4):303-306. doi:10.1177/ 1559827617700596
17. Wigal JK, Creer TL, Kotses H. The COPD self-efficacy scale. Chest. 1991;99(5):1193-1196. doi:10.1378/chest.99.5.1193

18. Müller K, Niermann C, Einhorn N, Kotschy-Lang N, Wagner P. Deutsche Übersetzung der COPD Self-Efficacy Scale: Entwicklung und ValidierungeinerKurzform [German Translation of the COPD Self-Efficacy Scale: development and Validation of a Short Form]. Psychother Psychosom Med Psychol. 2017;67(5):185-194. doi:10.1055/s-0042-121803

19. Emme C, Mortensen EL, Rydahl-Hansen S, Ostergaard B, Phanareth K. Danish version of 'The COPD self-efficacy scale': translation and psychometric properties. Scand $J$ Caring Sci. 2012;26(3):615-623. doi:10.1111/j.1471-6712.2011.00963.x

20. Bentsen SB, Rokne B, Wentzel-Larsen T, Henriksen AH, Wahl AK. The Norwegian version of the chronic obstructive pulmonary disease self-efficacy scale (CSES): a validation and reliability study. Scand $J \quad$ Caring Sci. 2010;24(3):600-609. doi:10.1111/j.14716712.2009.00731.x

21. Lee H, Lim Y, Kim S, et al. Predictors of low levels of self-efficacy among patients with chronic obstructive pulmonary disease in South Korea. Nurs Health Sci. 2014;16(1):78-83. doi:10.1111/nhs.12064

22. Santos CD, Santos AJ, Santos M, Rodrigues F, Bárbara C. Pulmonary rehabilitation adapted index of self-efficacy (PRAISE) validated to Portuguese respiratory patients. Pulmonology. 2019;25(6):334-339. doi:10.1016/j.pulmoe.2019.06.003

23. Vincent E, Sewell L, Wagg K, Deacon S, Williams J, Singh S. Measuring a change in self-efficacy following pulmonary rehabilitation: an evaluation of the PRAISE tool. Chest. 2011;140 (6):1534-1539. doi:10.1378/chest.10-2649

24. Jiang Y, Liu F, Guo J, et al. Evaluating an intervention program using WeChat for patients with chronic obstructive pulmonary disease: randomized controlled Trial. J Med Internet Res. 2020;22(4): e17089. doi:10.2196/17089

25. Shioya T, Sato S, Iwakura M, et al. Improvement of physical activity in chronic obstructive pulmonary disease by pulmonary rehabilitation and pharmacological treatment. Respir Investig. 2018;56(4):292-306. doi:10.1016/j.resinv.2018.05.002

26. Devins GM, Edwards PJ. Self-efficacy and smoking reduction in chronic obstructive pulmonary disease. Behav Res Ther. 1988;26 (2):127-135. doi:10.1016/0005-7967(88)90112-X

27. Lee H, Yoon JY, Lim Y, et al. The effect of nurse-led problem-solving therapy on coping, self-efficacy and depressive symptoms for patients with chronic obstructive pulmonary disease: a randomised controlled trial. Age Ageing. 2015;44(3):397-403. doi:10.1093/ageing/afu201

28. Bal Özkaptan B, Kapucu S. Home nursing care with the self-care model improves self-efficacy of patients with chronic obstructive pulmonary disease. Jpn J Nurs Sci. 2016;13(3):365-377. doi:10.1111/jjns. 12118

29. Chalfont G, Mateus C, Varey S, Milligan C. Self-efficacy of older people using technology to self-manage COPD, hypertension, heart failure, or dementia at home: an overview of systematic reviews. Gerontologist. 2021;61:e318-e334.

30. Andenæs R, Bentsen SB, Hvinden K, Fagermoen MS, Lerdal A. The relationships of self-efficacy, physical activity, and paid work to health-related quality of life among patients with chronic obstructive pulmonary disease (COPD). J Multidiscip Healthc. 2014;7:239-247.

31. Hanania NA, O'Donnell DE. Activity-related dyspnea in chronic obstructive pulmonary disease: physical and psychological consequences, unmet needs, and future directions. Int J Chron Obstruct Pulmon Dis. 2019;14:1127-1138. doi:10.2147/COPD.S188141

32. Liacos A, McDonald CF, Mahal A, et al. The Pulmonary Rehabilitation Adapted Index of Self-Efficacy (PRAISE) tool predicts reduction in sedentary time following pulmonary rehabilitation in people with chronic obstructive pulmonary disease (COPD). Physiotherapy. 2019;105(1):90-97. doi:10.1016/j.physio.2018.07.009 
33. Stellefson M, Paige SR, Alber JM, et al. Association between health literacy, electronic health literacy, disease-specific knowledge, and health-related quality of life among adults with chronic obstructive pulmonary disease: cross-sectional study. $J$ Med Internet Res. 2019;21(6):e12165. doi:10.2196/12165

34. McCabe C, McCann M, Brady AM. Computer and mobile technology interventions for self-management in chronic obstructive pulmonary disease. Cochrane Database Syst Rev. 2017;5(5): CD011425. doi:10.1002/14651858.CD011425.pub2

35. Long H, Howells K, Peters S, Blakemore A. Does health coaching improve health-related quality of life and reduce hospital admissions in people with chronic obstructive pulmonary disease? A systematic review and meta-analysis. Br J Health Psychol. 2019;24(3):515-546. doi:10.1111/bjhp. 12366

36. Keil DC, Stenzel NM, Kühl K, et al. The impact of chronic obstructive pulmonary disease-related fears on disease-specific disability. Chron Respir Dis. 2014;11(1):31-40. doi:10.1177/1479972313516881

37. Boeckxstaens P, Deregt M, Vandesype P, Willems S, Brusselle G, De Sutter A. Chronic obstructive pulmonary disease and comorbidities through the eyes of the patient. Chron Respir Dis. 2012;9 (3):183-191. doi:10.1177/1479972312452436

38. Kaplan RM, Ries AL. Quality of life: concept and definition. COPD. 2007;4(3):263-271. doi:10.1080/15412550701480356

39. Lopes AC, Xavier RF, Ac Pereira AC, et al. Identifying COPD patients at risk for worse symptoms, HRQoL, and self-efficacy: a cluster analysis. Chronic Illn. 2019;15(2):138-148. doi:10.1177/ 1742395317753883

40. Blackstock FC, Webster KE, McDonald CF, Hill CJ. Self-efficacy predicts success in an exercise training-only model of pulmonary rehabilitation for people with COPD. J Cardiopulm Rehabil Prev. 2018;38(5):333-341. doi:10.1097/HCR.0000000000000322
41. Khdour MR, Kidney JC, Smyth BM, McElnay JC. Clinical pharmacy-led disease and medicine management programme for patients with COPD. Br J Clin Pharmacol. 2009;68(4):588-598. doi:10.1111/j.1365-2125.2009.03493.x

42. Kar S, Zengin N. The relation between self-efficacy in patients with chronic obstructive pulmonary disease and caregiver burden. Scand $J$ Caring Sci. 2020;34(3):754-761. doi:10.1111/scs.12780

43. Ashford S, Edmunds J, French DP. What is the best way to change self-efficacy to promote lifestyle and recreational physical activity? A systematic review with meta-analysis. $\mathrm{Br} J$ Health Psychol. 2010;15(Pt 2):265-288. doi:10.1348/135910709X461752

44. Bartle NC, Harvey K. Explaining infant feeding: the role of previous personal and vicarious experience on attitudes, subjective norms, self-efficacy, and breastfeeding outcomes. $\mathrm{Br} J$ Health Psychol. 2017;22(4):763-785. doi:10.1111/bjhp.12254

45. Selzler AM, Rodgers WM, Berry TR, Stickland MK. Coping versus mastery modeling intervention to enhance self-efficacy for exercise in patients with COPD. Behav Med. 2020;46(1):63-74. doi:10.1080/ 08964289.2018.1561411

46. Kara M, Türkinaz AŞ. Effect of education on self-efficacy of Turkish patients with chronic obstructive pulmonary disease. Patient Educ Couns. 2004;55(1):114-120. doi:10.1016/j.pec.2003.08.006

47. Hawes EM, Pinelli NR, Sanders KA, et al. Post-hospital discharge care: a retrospective Cohort study exploring the value of pharmacist-enhanced care and describing medication-related problems. N C Med J. 2018;79(1):4-13. doi:10.18043/ncm.79.1.4

\section{Publish your work in this journal}

The International Journal of COPD is an international, peer-reviewed journal of therapeutics and pharmacology focusing on concise rapid reporting of clinical studies and reviews in COPD. Special focus is given to the pathophysiological processes underlying the disease, intervention programs, patient focused education, and self management protocols. This journal is indexed on PubMed Central, MedLine and CAS. The manuscript management system is completely online and includes a very quick and fair peer-review system, which is all easy to use. Visit http://www.dovepress.com/testimonials.php to read real quotes from published authors. 